\title{
Description of the Mechanism of Positive Inotropic Action of the Isoquinoline Alkaloid F-18
}

\author{
Shavkat Yu. Rustamov ${ }^{1 *}$, Inoyat Z. Jumayev' ${ }^{1}$, Sadriddin N. Boboev ${ }^{1}$, Eldor B. Ibragimov ${ }^{1}$, Pulat B. Usmanov ${ }^{1}$, Sherzod N. Zhurakulov $^{2}$ \\ ${ }^{1}$ Institute of Biophysics and Biochemistry, National University of Uzbekistan, Tashkent, Uzbekistan. \\ ${ }^{2}$ Institute of Chemistry of Plant Substances, Uzbek Academy of Sciences, Tashkent, Uzbekistan.
}

*Corresponding author: Shavkat Yu. Rustamov, Institute of Biophysics and Biochemistry, National University of Uzbekistan, Tashkent, Uzbekistan.

\section{Received Date: May 17, 2021; Accepted Date: May 28, 2021; Published Date: June 04, 2021}

Citation: Shavkat Y Rustamov, Inoyat Z Jumayev, Sadriddin N Boboev, Eldor B Ibragimov, Pulat B Usmanov, et al. (2021) Description of the Mechanism of Positive Inotropic Action of the Isoquinoline Alkaloid F-18. Cardiology Research and Reports. 3(3): DOI:10.31579/2692-9759/023

Copyright: () 2021 Shavkat Yu. Rustamov. This is an open-access article distributed under the terms of the Creative Commons Attribution License, which permits unrestricted use, distribution, and reproduction in any medium, provided the original author and source are credited.

\begin{abstract}
This study evaluated the mechanism of inotropic effect of an isoquinoline alkaloid derivative, $1-\left(2^{\prime}\right.$-bromine- $4^{\prime}, 5^{\prime}$ dimethoxyphenyl)-6,7-dimethoxy-1,2,3,4- tetrahydroisoquinoline (F-18) using electrically stimulated rat left ventricular papillary muscle of rat. The F-18 alkaloid have been shown to have positive inotropic effect on papillary muscle contraction activity, IC50 value $-14,6 \mu \mathrm{M}$. $\mathrm{Ca}^{2+} \mathrm{L}$-channel blocker - nifedipine was used in experiments. Inotropic effects of F-18 isoquinoline alkaloid on cardiomyocytes were suggested, based on results obtained in experiments carried in cardiomyocytes SR $\mathrm{Ca}^{2+}$ - transport systems modulation.

Key words: papillary muscle; inotropic effect; isoquinoline alkaloid
\end{abstract}

\section{Introduction}

Isoquinoline alkaloids constitute one of the largest groups of plantderived compounds with a wide range of pharmacological activities are a promising candidate for developing new cardiovascular drugs. A significant number of isoquinoline alkaloids possess a potent antiarrhythmic activity mediated through multiple cellular mechanisms (Inoyat Jumayev, 2020). The antiarrhythmic effect of the well-known representative of these alkaloids tetrandrine are provided by blockage of L- and T-types calcium and sodium channels with slow recovery kinetics, thus terminating acute episodes of paroxysmal supraventricular tachycardia (Andrew et al.,2000). It also has been demonstrated that tetrandrine exerted a substantial positive inotropic and chronotropic effects associated with decreased intracellular $\mathrm{Ca}^{2+}$ due to the blockage of the voltage-operated $\mathrm{Ca}^{2+}$ channels and modulation of the sarcoplasmic reticulum $\mathrm{Ca}^{2+}$ loading and release functions (Gerald et al., 2015).
Positive inotropic of tetrandrine, like most antiarrhythmic drugs, resulting in reductions in cardiac contractility and cardiac output is a serious adverse effect, limit its use in patients with already impaired left ventricular function (Ahmad et al., 2012).

Recently, with the aim to find new effective antiarrhythmic agents a series of hydroxyethyl derivatives of 1-aryltetraisoquinoline alkaloids were synthesized (Zhurakulov et al., 2013; Zhurakulov et al.2014). In previous studies the effects of these derivatives on rat left ventricular papillary muscle contractility we found that among them the most potent positive inotropic activity exert 1-(2'-bromine-4',5'-dimethoxyphenyl)-6,7dimethoxy-1,2,3,4-tetrahydroisoquinoline, designated as F-18. Therefore, the aim of this study was further to characterize the positive inotropic effect of this new isoquinoline derivative and to define the mechanism of this action.

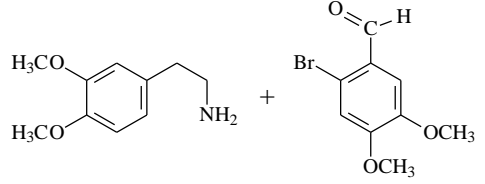

2à
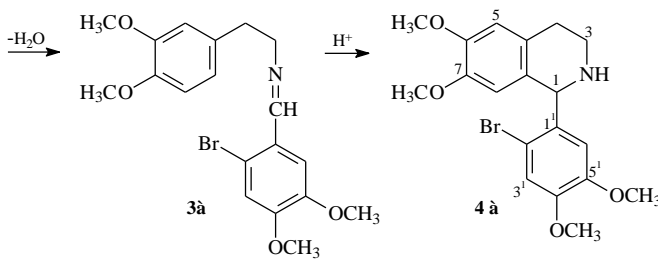

Figure 1: Chemical structure of isoquinoline alkaloid. 
The chemical structure of the synthesized 1-(2'-bromine- $4^{\prime}, 5^{\prime}-$ dimethoxyphenyl)-6,7-dimethoxy-1,2,3,4- tetrahydroisoquinoline is proven with the help of NMR data ${ }^{1} \mathrm{~N}$ and ${ }^{13} \mathrm{C}$ spectra. In NMR ${ }^{1} \mathrm{~N}$, the spectrum of the protons of the aromatic ring N-5 and N-8 is observed in the form of singlets at $6.64 \mathrm{ppm}$. VA $\delta 6.26 \mathrm{ppm}$, the $\mathrm{n}-1$ of the methyine group resonates in the form of a singlet at $\delta 5.43 \mathrm{ppm}$. Signals NMR ${ }^{1} \mathrm{~N}$ and ${ }^{13} \mathrm{C}$ confirmed education 1-(2'-bromine- $4^{\prime}, 5^{\prime}$-dimethoxyphenyl)-6,7dimethoxy-1,2,3,4- tetrahydroisoquinoline (4a) $\mathrm{C}_{19} \mathrm{H}_{22} \mathrm{O}_{4} \mathrm{NBr}$.

\section{Material and Methods}

All experimental protocol and conditions for preoperative care were approved by the animal use committee of the Institute of Biophysics and Biochemistry. Adult male Wistar rats weighing 200-250g were anesthetized with sodium pentobarbital $\left(50 \mathrm{mg} / \mathrm{kg}^{-1}\right.$, i.p. $)$ and then sacrificed by cervical dislocation. The papillary muscles from the left ventricles of the rat hearts about $0,5-0,8 \mathrm{~mm}$ in diameter and $1-3 \mathrm{~mm}$ in length were dissected and mounted in a tissue bath (STEIRT, HSE, Germany) of $3 \mathrm{ml}$ volume and superfused at a rate of $20 \mathrm{ml} \mathrm{min}^{-1}$ with Krebs solution. The composition of the Krebs solution was (in $\mathrm{mM}$ ) $\mathrm{NaCl}$, 118; $\mathrm{KCl}, 4.7 ; \mathrm{MgSO}_{4}, 1.2 ; \mathrm{KH}_{2} \mathrm{PO}_{4}, 1.2$; glucose $10 ; \mathrm{NaHCO}_{3}, 24$; $\mathrm{CaCl}_{2}, 2.54$. The solution was continuously gassed with $95 \% \mathrm{O}_{2}$ and $5 \%$ $\mathrm{CO}_{2}$ to give a $\mathrm{pH}$ of 7.4 and was maintained at $37^{\circ} \mathrm{C}$. Preparation of tissue and measurement of contractility and setup of the equipment

In experiments the papillary muscles preparations, isolated from the right atrium of adult albino rats' hearts. Rats were deeply anaesthetized with diethyl prior to paralyzing by using cervical dislocation method. The papillary muscles were $-0.4-1.3 \mathrm{~mm}$ in diameter and $2.5-3.8 \mathrm{~mm}$ in length. Isometric tension forces were recorded using a force transducer (SIKG20, World Precision Instruments, Inc. 175 Sarasota Center Boulevard, Florida 34240-9258, USA), designed for the in vitro study in standard pharmacological experiments for measuring contraction force response of isolation muscle preparations. The organ chamber $(20 \mathrm{ml})$ was part of the experimental setup, as shown in Figure 2. For further details of setup of the recording system is given in the text.

The Isometric force transducer SI-KG20 is connected to a transducer amplifier (SI-BAM21-LCB, WPI, Inc. 175 Sarasota Center Boulevard, Florida 34240-9258, USA). The papillary muscle was lifted with electric impuls that was higher than threthold $(-20 \%)$, rectangular, electrical pulses of frequency $0.5 \mathrm{~Hz} ; 5-10 \mathrm{msec}$ and $5 \mathrm{~V}$ amplitude, delivered via a pair of platinum electrodes placed in the muscle-mounting organ chamber by using stimulator ESL-2 (Russia).

\section{Drugs and Reagents.}

The derivative of isoquinoline alkaloid 1-(2'-bromine-4',5'dimethoxyphenyl)-6,7-dimethoxy-1,2,3,4- tetrahydroisoquinoline (F-18) was synthesized by the Bischler-Napieralski cyclization with 3,4disubstituted phenethylamine and aromatic acetic acid as starting materials in Institute of Plant compounds Uzbek Academy of Sciences.

Nifedipine, lidocaine were purchased from Sigma-Aldrich Chimie (Sigma, St. Louis, MO, U.S.A.).

Data are expressed as mean \pm SD. Control values between groups were compared by analysis of variance. The Student's $t$-test was used to compare two means. A probability of less than 0.05 was taken as a statistically significant difference. Statistical analysis was performed using OriginPro 7.5 software (OriginLab Co., U.S.A).

\section{Results and Discussion}

The large number of data received in recent years testifies to the development of energy metabolism in cardiomococytes to play a leading role in the development of pathological processes in the heart. It causes dysfunction of the ryanodine receptor (RyR2), sarcoplasmic reticulum $\mathrm{Ca}^{2+}$ ATPaseis (SERCA2a), $\mathrm{Na}^{+} / \mathrm{Ca}^{2+}$ exchanger in the absence of ATF[Bo Sun et al, 2018].

When we tested the dose-dependent effect of the F-18 alkaloid on rat heart papillary muscle contraction activity, it was found that this alkaloid had a positive inotropic effect at all concentrations. Initially, the F-18 alkaloid showed no significant effect on the contraction force of papillary muscle from $1 \mu \mathrm{M}$ to $5 \mu \mathrm{M}$, and a positive inotropic effect from $5 \mu \mathrm{M}$ was observed. The F-18 alkaloid was found to have a maximal effect at $45 \mu \mathrm{M}$ and an increase in muscle contraction force relative to control $65.6 \pm 4.4 \%$ (Figure 2 ). The semi-maximum effective concentration $\left(E C_{50}\right)$ of the alkaloid F-18 was $14.6 \mu \mathrm{M}$, respectively.

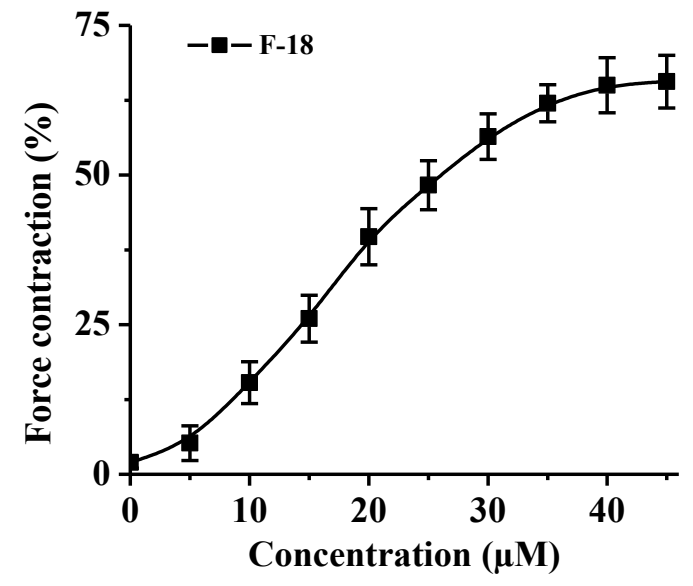

Figure 2: Positive inotropic effect of isoquinoline alkaloids.

The ordinate axis shows the pulsating force of the papillary muscle, expressed as a percentage of the maximum value of $100 \%$. The stimulation frequency is $0.5 \mathrm{~Hz}\left(t=+36 \pm 0.5^{\circ} \mathrm{C}\right) . P<0.01(\mathrm{n}=6)$.

It is known that the basis of the inotropic effect of various pharmacological agents on myocardial contractile activity lies in the change in the amount of $\left[\mathrm{Ca}^{2+}\right]_{\text {in }}$ cardiomyocytes, which occurs through the modulation of the activity of various $\mathrm{Ca}^{2+}$-transport systems [ $\AA$ smund et al, 2015]. One of the main causes of positive inotropism is due to the modulation of $\mathrm{Ca}^{2+} \mathrm{L}$-channel activity in cardiomyocytes and, in turn, the change $\left[\mathrm{Ca}^{2+}\right]_{i n}$. In subsequent experiments, the positive inotropic effect of the alkaloid F-18 on the activity of the potential-activating $\mathrm{Ca}^{2+} \mathrm{L}$ - 
channel located in the cardiomyocyte sarcolemma was carried out in the presence of a specific blocker of the $\mathrm{Ca}^{2+} \mathrm{L}$-channel - nifedipine $\left(I C_{50}-\right.$ $0.01 \mu \mathrm{M})$. It was found that the positive inotropic effect of F-18 $(45 \mu \mathrm{M})$ in the presence of nifedipine $0.01 \mu \mathrm{M}$ in the medium was $21.7 \pm 3.8 \%$, respectively, relative to the control (Figure 3).
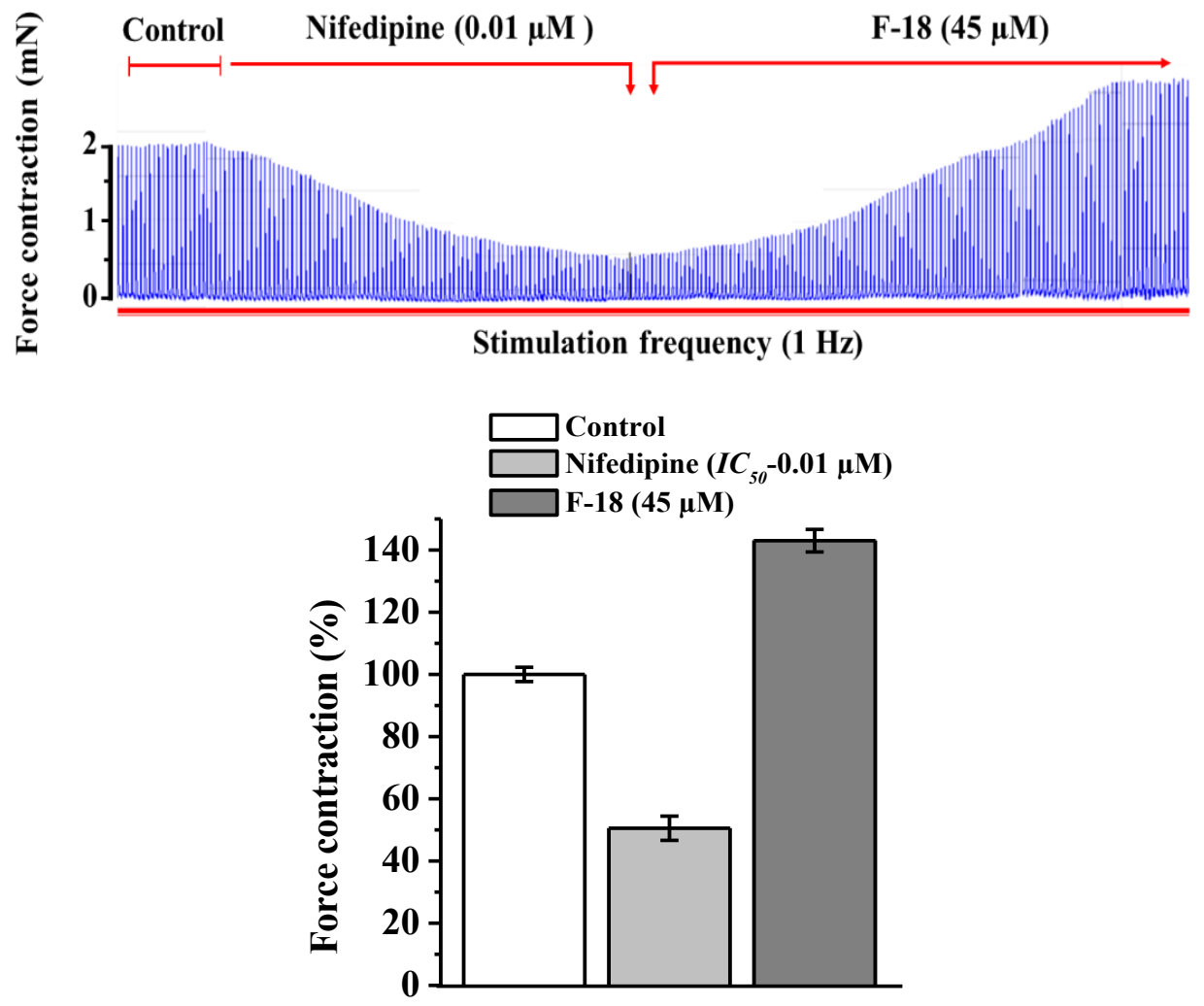

Figure 3: Comparison of the inotropic effects of $F$-18 alkaloid and nifedipine on the contraction force of extracted rat papillary muscle. Stimulation: $0.5 \mathrm{~Hz}, 5 \mathrm{~V}, 5 \mathrm{msec},+36 \pm 0.5^{\circ} \mathrm{C}$, resting tension $=10 \mathrm{mN} . P<0.05$ indicates value compared to control $(n=5)$.

From this experiment, it can be concluded that the positive inotropic effect of the alkaloid F-18 indicates a low involvement of potential-dependent activating $\mathrm{Ca}^{2+} \mathrm{L}-$ channels located in the cardiomyocyte sarcolemma, as well as the presence of other mechanisms.

$\mathrm{Ca}^{2+}$ ions from SR play an important role in the process of contraction of the heart muscle. In subsequent experiments, the effect of the F-18 alkaloid on the positive inotropic effect on $\mathrm{SR} \mathrm{Ca}^{2+}$ concentration was studied. The post-rest potency method was used to assess the effect of SR $\mathrm{Ca}^{2+}$. The process of post-rest potentiation is explained by a sharp increase in the initial contraction force when this heart muscle excitation is stopped for 30 seconds and resumed after a certain period of rest. After 30 seconds of rest, cardiomyocytes accumulate more $\mathrm{Ca}^{2+}$ ions than in the previous physiological order of SR, and more $\mathrm{Ca}^{2+}$ ions are released into the

A

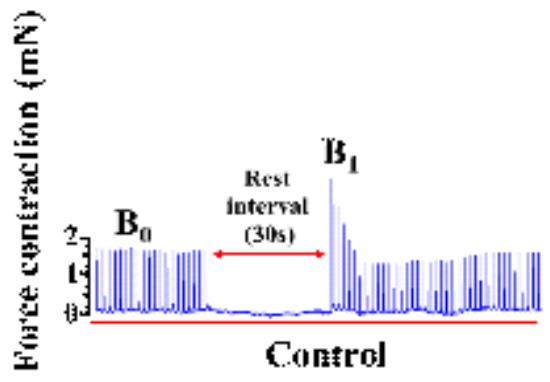

cytosol when reactivation is given. In this case, a sharp increase in the initial contraction force is observed. Post-rest potency is an adequate method widely used in the study of changes in $\mathrm{SR} \mathrm{Ca}^{2+}$ concentration in cardiomyocytes [Burkert et al, 1998].

In our control experiments, the amplitude of the first contraction force was set to $100 \%$ when the papillary muscle stimulation was stopped for $30 \mathrm{~s}$ and returned to the previous excitation. Under these conditions, the F-18 alkaloid was found to increase the post-rest potency value by $157.4 \pm 4.1 \%$ relative to the control under the influence of $45 \mu \mathrm{M}$ (Figure 4). According to the analysis of the results of this experiment, it can be assumed that the positive inotropic effect of the alkaloid F-18 increases the concentration of $\left[\mathrm{Ca}^{2+}\right]_{i}$ in cytosol by activating SR function.

B

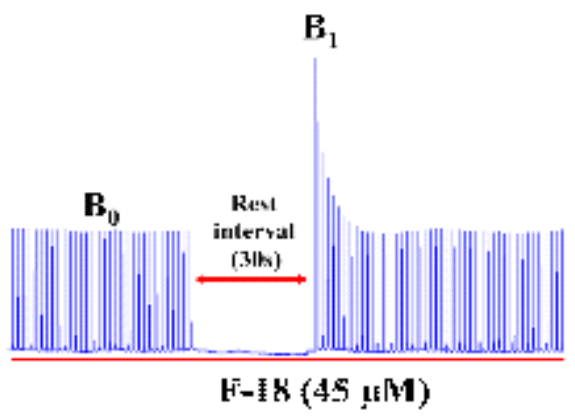


C

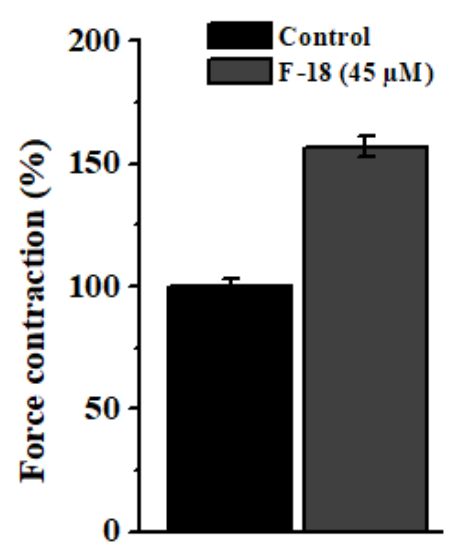

Figure4: The effect of $F-18$ on the post-rest potentiation of contraction in rat papillary muscle. (A, B) Representative tracing shows the development of post-rest potentiation of contraction after $30 \mathrm{~s}$ rest period in the absence $(A)$ and presence $(B)$ of $F-18(45 \mu M)$. (C) The relative potentiation of contraction before and after administration of $45 \mu M F-18$.

Data are reported as mean \pm SEM $(n=5)$ and expressed as a percentage of control contraction, obtained in normal Krebs solution at $0.1 \mathrm{~Hz}$ before the addition of drugs, which was taken as $100 \% . P<0.05$ vs baseline.

\section{Conclusion}

All of the above experiments show that the positive inotropic effect of the alkaloid F-18 partially affects the potential-activating $\mathrm{Ca}^{2+} \mathrm{L}$-channels located in the cardiomyocyte sarcolemma and mainly affects the SR function, increasing the amount of $\mathrm{Ca}^{2+} \mathrm{L}$ ions released, resulting in postrest potency in papillary muscle an increase in the value is observed. The positive inotropic effect of the F-18 alkaloid is explained by its effect on SR by increasing the amount of $\mathrm{Ca} 2+$ ions accumulated and excreted.

\section{Conflict of Interest}

The authors have declared that no conflict of interest exists.

Acknowledgements. This work was supported by a grant FA-F6-004 from the Coordinating Committee for Development of Science and Technology under the Cabinet of Ministers of the Republic of Uzbekistan.

\section{References}

1. Inoyat Jumayev, Pulat Usmanov, Shavkat Rustamov, Sherzod Zhurakulov. (2020) Comparative inotropic effects of the some isoquinoline alkaloids // Biomedical and Pharmacology Journal. 13(1), p. 325-333.

2. Andrew A. Grace, A. John Cam. (2000) Voltage-gated calciumchannels and antiarrhythmic drug action. Cardiovascular Research $45 ; 43-51$.

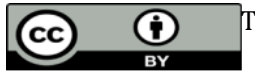

This work is licensed under Creative Commons Attribution 4.0 License

To Submit Your Article Click Here: Submit Manuscript

DOI: $10.31579 / 2692-9759 / 023$
3. Gerald W. Zamponi, Joerg Striessnig, Alexandra Koschak, and Annette C. Dolphin. (2015) The Physiology, Pathology, and Pharmacology of Voltage-Gated Calcium Channels and Their Future Therapeutic Potential. Pharmacol Rev. 7(4): 821-870.

4. Ahmad Amin and Majid Maleki. (2012) Positive inotropes in heart failure: a review article Heart Asia. 4(1): 16-22.

5. Zhurakulov ShN, Levkovich MG, Vinogradova VI. (2014) Synthesis of Hydroxyethyl Perivatives of 1aryltetrahydroisoquinoline alkaloids. Chemistry of Natural Compounds, 49: 1095-1098.

6. Zhurakulov ShN, Vinogradova VI, Levkovich MG. (2013) Synthesis of 1-aryltetrahydroisoquinoline alkaloids and their analogs. Chemistry of Natural Compounds. 49: 70-74.

7. Bo Sun, Jinhong Wei, Xiaowei Zhong, Wenting Guo, Jinjing Yao, Ruiwu Wang, Alexander Vallmitjana, Raul Benitez, Leif HoveMadsen, S R Wayne Chen. (2018) The cardiac ryanodine receptor, but not sarcoplasmic reticulum $\mathrm{Ca} 2+-\mathrm{ATPase}$, is a major determinant of $\mathrm{Ca} 2+$ alternans in intact mouse hearts // J Biol Chem.293(35):13650-13661.

8. Åsmund T. Røe, Michael Frisk, and William E. Louch. (2015) Targeting Cardiomyocyte $\mathrm{Ca} 2+$ Homeostasis in Heart Failure // Curr Pharm Des. 21(4): 431-448.

9. Burkert Pieske, Melanie Sütterlin, Stephan Schmidt-Schweda, Kitzatomo Minami, Markus Meyer, Manfred Olschewski, Christian Holubarsch, Hanjörg Just, and Gerd Hasenfuss. (1996) Diminished Post-Rest Potentiation of Contractile Force in Human Dilated Cardiomyopathy // J. Clin. Invest. Vol. 98, Number 3, 764-776.
Ready to submit your research? Choose Auctores and benefit from:

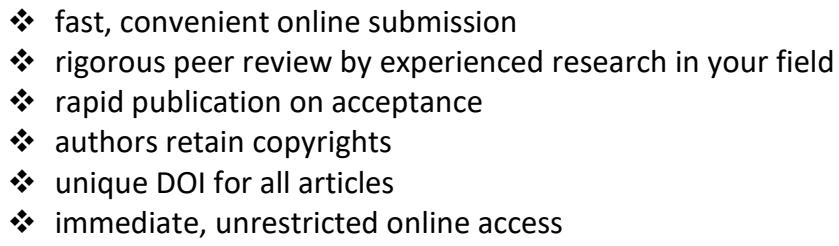

At Auctores, research is always in progress.

Learn more www.auctoresonline.org/journals/cardiology-research-andreports 